\title{
Time trends in the prevalence of peanut allergy: three cohorts of children from the same geographical location in the UK
}

\author{
C. Venter ${ }^{1,2}$, S. Hasan Arshad ${ }^{1}$, J. Grundy ${ }^{1}$, B. Pereira ${ }^{1}$, C. Bernie Clayton ${ }^{1}$, K. Voigt $^{1}$, B. Higgins ${ }^{2}$ \& \\ T. Dean ${ }^{1,2}$
}

${ }^{1}$ The David Hide Asthma and Allergy Research Centre, St. Mary's Hospital, Newport, Isle of Wight, UK; ${ }^{2}$ School of Health Sciences and Social Work, University of Portsmouth, Portsmouth, UK

To cite this article: Venter C, Hasan Arshad S, Grundy J, Pereira B, Bernie Clayton C, Voigt K, Higgins B, Dean T. Time trends in the prevalence of peanut allergy: three cohorts of children from the same geographical location in the UK. Allergy 2010; 65: 103-108

\section{Keywords}

adverse food reactions; epidemiology; food

allergy; peanut allergy; prevalence.

\section{Correspondence}

T. Dean, School of Health Sciences and Social Work, University of Portsmouth, James Watson West, 2 King Richard 1st Road, Portsmouth PO1 2FR, UK.

Accepted for publication 2 July 2009

DOI:10.1111/j.1398-9995.2009.02176.x

Edited by: Bodo Niggemann

\begin{abstract}
Background: This article investigated the prevalence of peanut allergy in three cohorts of children born in the same geographical location, Isle of Wight, UK and seeks to determine whether the prevalence of peanut allergy has changed between 1994 and 2004.

Methods: Three cohorts of children (age 3-4 years) born on the Isle of Wight, were assessed for peanut allergy and the outcomes compared: Cohort A: Born in 1989; reviewed at 4 years of age $(n=2181)$.

Cohort B: Born between 1994 and 1996; reviewed between 3 and 4 years of age $(n=1273)$.

Cohort C: Born between 2001 and 2002; reviewed at 3 years of age $(n=891)$.

Results: Peanut sensitization increased significantly from $1.3 \%$ in Cohort A to $3.3 \%$ $(P=0.003)$ in Cohort B before falling back to $2.0 \%$ in Cohort $\mathrm{C}(P=0.145)$. Similarly, clinical peanut allergy increased significantly from $0.5 \%$ in Cohort A to $1.4 \%(P=0.023)$ in Cohort $\mathrm{B}$, with a subsequent fall to $1.2 \%$ in Cohort $\mathrm{C}$ $(P=0.850)$.

Conclusions: Our data from three cohorts of 3- to 4-year-old children born in the same geographical area shows that peanut allergy prevalence has changed over time. Peanut sensitization and reported allergy in children born in 1994-1996 increased from 1989 but seems to have stabilized or slightly decreased since the late 1990s, although not significant.
\end{abstract}

Food hypersensitivity is believed to affect $1.5 \%$ of adults and $6-8 \%$ of children (1-7) and vary widely according to the populations studied for most foods (8). Peanut is reported as the most common food causing severe IgE-mediated reactions in children and adolescents in the USA and Europe (9, 10).

In the UK three studies reported on the prevalence of peanut allergy $(11,12)$. On the Isle of Wight the prevalence of peanut allergy has been reported to be $1 \%$ in 11 year olds and $0.8 \%$ in 15 year olds, (7) with a peanut sensitization of $0.4 \%$ in 1 year olds (6). Hourihane et al. (11) reported recently, a peanut allergy prevalence rate of $1.8 \%$ in 5 -yearold children in the UK. In addition Du Toit et al. (12) reported a prevalence of self-reported peanut allergy in 4-18year-old children in the UK of $1.85 \%$.
Based on the Isle of Wight data, we have previously reported an increase in the prevalence in peanut sensitization and clinical allergy between two cohorts of children born 6 years apart (13). This study reports on the prevalence of peanut allergy in a cohort of children born in 2001-2002 and seeks to determine whether the prevalence of peanut allergy has changed since 1994-1996.

\section{Methods}

Three cohorts of children born on the Isle of Wight were assessed at the David Hide Asthma and Allergy Research Centre for peanut sensitization and clinical symptoms:

Cohort A: Born in 1989; reviewed at 4 years of age $(n=2181)$. 
Cohort B: Born between 1994 and 1996; reviewed between 3 and 4 years of age $(n=1273)$.

Cohort C: Born between 2001and 2002; reviewed at 3 years of age $(n=891)$.

Characteristics of Cohort A (14) and Cohort B (13, 15) have previously been described.

In brief, for Cohort A, a birth cohort of 1456 children was recruited over a 14-month period (1989-1990). At 4 years, 1218 (used as denominator for clinical allergy) children were reviewed and 981 (used as denominator for sensitization) children were skin prick tested (SPT) with a battery of 12 common allergens. For Cohort B, 2858 3- to 4-year-old children were recruited into a study looking at food additives and behaviour (15). Parents of 1273 children (used as denominator for clinical allergy) agreed to participate in this study looking at peanut allergy and 1246 (used as denominator for sensitization) children consented to a SPT and were included in the results for that article. Diagnosis of peanut allergy was made by means of an open food challenge (OFC).

For Cohort C, 969 infants were recruited into a study looking at the prevalence and cumulative incidence of food hypersensitivity (5). Parents of 891 children (used as denominator for clinical allergy) agreed to participate in this study looking at peanut allergy and 642 (used as denominator for sensitization) children/parents consented to a SPT and were included in the results for that article. Children were SPT to a standard battery of allergens including house dust mite, cat, grass, milk, egg, wheat, cod fish, sesame and peanut. Skin prick tests were conducted with commercial extracts obtained from Soluprick SQ allergens-ALK Allergologisk Laboratorium A/S (Horsholm, Denmark). Similar SPT methodology was used as for Cohort A and Cohort B. Diagnosis of peanut allergy was made by means of an OFC. These peanut challenges were only conducted at 3 years of age as it is considered that infants should not be exposed to these foods in the first few years of life as recommended by the COT report $(5,16)$ Those with a positive reaction were invited to participate in a double-blind, placebo-controlled food challenge (DBPCFC) but none of the parents were prepared to consent to this.

Approval for the study was obtained from the Isle of Wight, Portsmouth and South East Hampshire Local Research Ethics Committee (Ref 09/01).

The following definitions were used for the purpose of this study:

Sensitization to peanuts: This was defined as wheal size $\geq 3 \mathrm{~mm}$ in the presence of a negative control in all three cohorts.

Clinical peanut allergy: This was defined as a positive SPT with a convincing clinical history or a positive OFC (Cohorts $\mathrm{B}$ and $\mathrm{C}$ ) that is all children sensitized to peanut who have not eaten peanut underwent food challenges. In Cohort A, the diagnosis of clinical peanut allergy was based on convincing clinical history alone and challenges were not performed. Those who had a positive SPT in Cohort C, but who had not eaten peanut at that stage, underwent specific $\operatorname{IgE}$ tests and were followed by the Allergy Centre until they consumed peanut without a reaction.
Overall atopy: This was defined as a positive SPT ( $\geq 3 \mathrm{~mm}$ ) to any allergen that was tested in all three cohorts. These included house dust mite, cat, grass, milk, egg and peanut.

\section{Statistical analysis}

All data were double entered by different operators on SPSS versions 10 and 11 and were compared and verified (SPSS Inc., Chicago, IL, USA). The incidence of sensitization and allergy across the three cohorts was examined using Chisquare tests in which the linear and quadratic components of trend have been isolated. The effect of exposure to different factors has been quantified using Odds Ratios with 95\% confidence limits derived using conditional likelihood estimation. Missing data was not included in the calculations.

\section{Results}

\section{Sensitization status}

For Cohort A, 1218 (88\% of the original cohort) children were reviewed at 4 years and 981 children were SPT (14). Thirteen $(1.3 \% ; 13 / 981)$ were sensitized to peanut.

For Cohort B, 1273 children were seen at three years of age and 1246 of this cohort were SPT to peanut (13). Forty one $(3.3 \% ; 41 / 1246)$ children had a positive SPT to peanut.

In Cohort C, 891 children were reviewed at 3 years of age (used as denominator for clinical allergy) and SPT were performed on 642 (used as denominator for sensitization) children. Thirteen children $2.0 \% \quad(95 \%$ CI $1.08-3.43)$ were sensitized to peanut.

Comparing the three cohorts, prevalence of sensitization to peanut rose from $1.3 \%$ to $3.3 \%$ in Cohorts $\mathrm{A}$ and $\mathrm{B}$ $(P=0.003)$ (Fig. 1) after which it fell back to $2.0 \%$, although the decline failed to reach statistical significance $(P=0.145)$.

For Cohort C, of the children sensitized to peanut, $53.9 \%$ suffered from current wheeze (i.e. wheeze in the last 12 months) and $61.5 \%$ were diagnosed with eczema in the past (Table 1). Parents of children sensitized to peanut were significantly more likely to report their children having wheezed in the last 12 months $(P=0.012)$ and eczema in the past $(P=0.002)$. They were also commonly sensitized to

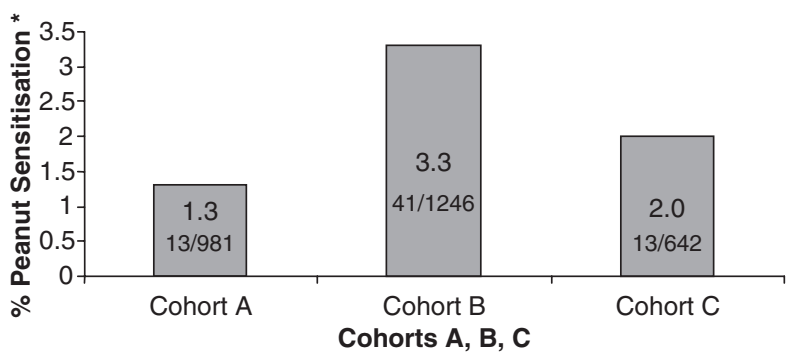

Figure 1 Comparison of sensitization to peanuts in three cohorts of children aged 3-4 years. *Test for trend: Chi-square (quadratic component) $P=0.005$. 
Table 1 Allergic morbidity amongst children sensitized to peanut compared to those not sensitized (Cohort C)

\begin{tabular}{lccc}
\hline Allergic disorders & $\begin{array}{l}\text { Sensitized to peanut, } \\
(n=13)(\%)\end{array}$ & $\begin{array}{l}\text { Not sensitized to peanut, } \\
(n=629)(\%)\end{array}$ & OR (95\% Cl) \\
\hline Ever wheeze & $7(53.8)$ & $173(27.5)$ & $3.08(0.87-11.22)$ \\
Wheeze in the last 12 months & $7(53.9)$ & $136(21.6)$ & $4.23(1.19-15.46)$ \\
Ever diagnosed eczema by a & $8(61.5)$ & $127(20.2)$ & $6.32(1.78-24.91)$ \\
$\quad$ doctor & & & 0.056 \\
\hline
\end{tabular}

Table 2 Atopic sensitization in children sensitized to peanut compared to those not sensitized to peanuts (Cohort C)

\begin{tabular}{|c|c|c|c|c|}
\hline $\begin{array}{l}\text { Skin test } \\
\text { positivity }\end{array}$ & $\begin{array}{c}\text { Sensitized } \\
\text { to peanut, } \\
(n=13) \\
(\%)\end{array}$ & $\begin{array}{c}\text { Not } \\
\text { sensitized } \\
\text { to peanut, } \\
(n=629) \\
(\%)\end{array}$ & OR (95\% Cl) & $P$-value \\
\hline $\begin{array}{l}\text { House } \\
\text { dust mite }\end{array}$ & $9(69.2)$ & $34(5.4)$ & $39.4(10.2-134.4)$ & $<0.001$ \\
\hline Grass & $2(15.4)$ & $19(3.0)$ & $5.84(0.6-29.5)$ & 0.064 \\
\hline Cat & $3(23.1)$ & $23(3.7)$ & 7.90 (1.3-33.3) & 0.013 \\
\hline Milk & $1(7.7)$ & $2(0.3)$ & $26.1(0.4-521.1)$ & 0.06 \\
\hline Egg & $4(30.8)$ & $5(0.8)$ & $55.5(9.1-298.5)$ & $<0.001$ \\
\hline Wheat & $1(7.7)$ & $7(1.1)$ & $7.40(0.2-65.2)$ & 0.152 \\
\hline Fish (cod) & $3(23.1)$ & $0(0)$ & NA & - \\
\hline Sesame & $5(38.5)$ & $4(0.6)$ & $97.7(16.7-565.1)$ & $<0.001$ \\
\hline
\end{tabular}

Table 3 Atopic sensitization in children ever diagnosed with eczema (Cohort C)

\begin{tabular}{|c|c|c|c|c|}
\hline $\begin{array}{l}\text { Skin test } \\
\text { positivity }\end{array}$ & $\begin{array}{c}\text { Ever } \\
\text { diagnosed } \\
\text { with eczema } \\
\text { over } 3 \text { years } \\
(n=201)(\%)\end{array}$ & $\begin{array}{c}\text { Not } \\
\text { diagnosed } \\
\text { with eczema } \\
\text { over } 3 \text { years } \\
(n=690)(\%)\end{array}$ & OR $(95 \% \mathrm{Cl})$ & $P$-value \\
\hline $\begin{array}{l}\text { House } \\
\text { dust mite }\end{array}$ & 32 (15.9) & $11(1.6)$ & $11.9(5.9,26.5)$ & $<0.001$ \\
\hline Cat & $12(6.0)$ & $14(2.0)$ & $3.1(1.3,7.3)$ & 0.007 \\
\hline Egg & $8(4.0)$ & $1(0.15)$ & $28.6(3.8,1270)$ & $<0.001$ \\
\hline Peanut & $9(4.5)$ & $4(0.6)$ & $8.0(2.2,36.0)$ & 0.001 \\
\hline Sesame & $6(3.0)$ & $3(0.44)$ & $7.0(1.5,43.8)$ & 0.006 \\
\hline
\end{tabular}

other allergens (Table 2). Children sensitized to peanut were significantly more likely to be sensitized to House Dust Mite $(P<0.001)$, Cat $(P=0.013)$, Egg $(P<0.001)$ and Sesame $(P<0.001)$ than children not sensitized to peanut.

Children who were diagnosed with eczema over the course of the 3 years, were significantly more likely to be sensitized to house dust mite $(P<0.001)$, cat $(P=0.007)$, egg $(P<0.001)$, peanut $(P=0.001)$ and sesame $(P=0.006)$ (Table 3). Children who were sensitized to egg were also more likely to be sensitized to house dust mite $(P<0.001)$, cat $(P=0.004)$ and peanut $(P<0.001)$, but not sesame $(P>0.999)$ (Table 4).

\section{Clinical diagnosis}

For Cohort A, 6 of $1218(0.5 \%)$ children were diagnosed with peanut allergy based on their sensitization status and clinical history and for Cohort B 18 children $(1.4 \% ; 18 /$ 1273) were diagnosed with peanut allergy based on food challenge/clinical history and sensitization status.

For Cohort C, 13/642 were sensitized to peanut and 11/ $891(1.2 \% ; 11 / 891)$ children were diagnosed with peanut allergy. Three children were diagnosed by means of a positive OFC. Eight children were not challenged due to a convincing history of clinical reaction coupled with positive skin prick test (SPT size: 4.25, 6, 6, 8, 9, 10, 12 and $11 \mathrm{~mm}$ ). There was no difference in the number of breastfeeding mothers or mothers who reported avoiding peanuts during breastfeeding between those sensitized to peanut or not.

Comparing the three cohorts, clinical peanut allergy increased significantly from $0.5 \%$ to $1.4 \%$ in Cohort A and B $(P=0.023)$ with a subsequent fall to $1.2 \%$, although this was not statistically significant $(P=0.850)$ (Fig. 2).

\section{Overall atopy}

In Cohort A, 12.3\% (150/1218) children were diagnosed with overall atopy, $15 \%$ in Cohort B (185/1246) and $11.7 \%$ (75/ 642) in Cohort C.

There was no significant difference when sequentially comparing the three groups (A $v s$ B and B $v s$ C) (Fig. 3) in terms of overall atopy.

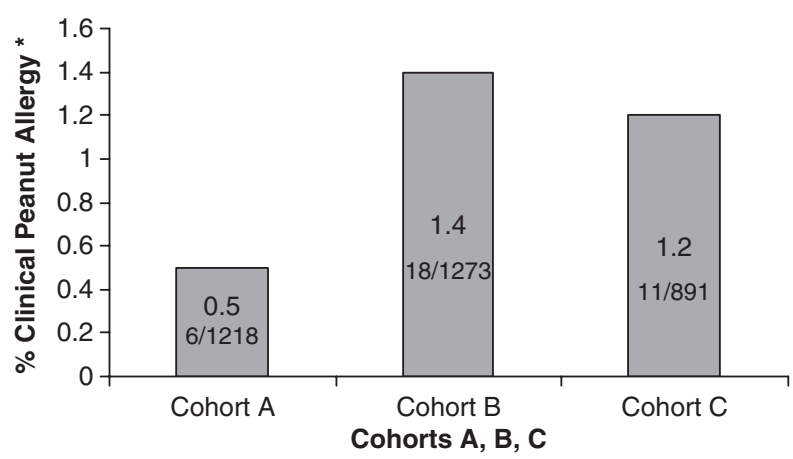

Figure 2 Comparison of peanut allergy in three cohorts of children aged $3-4$ years. ${ }^{*}$ Test for trend: Chi-square (quadratic component) $P=0.127$. 


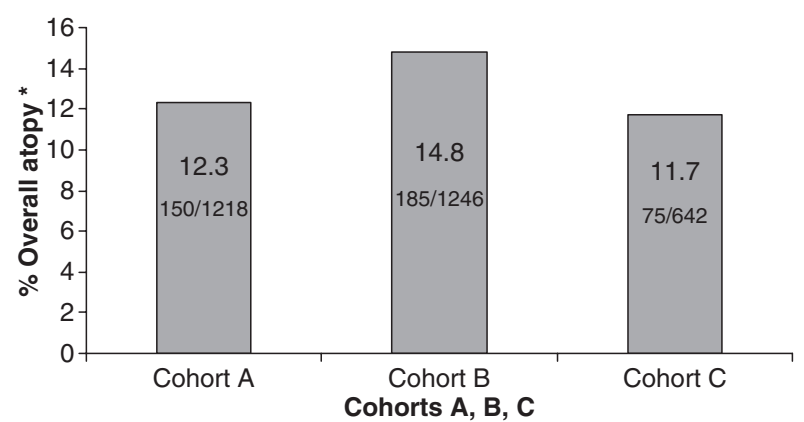

Figure 3 Comparison of overall atopy in three cohorts of children aged 3-4 years. ${ }^{*}$ Test for trend: Chi-square (quadratic component) $P=0.024$.

Table 4 Atopic sensitization to other aero- and food allergens in children sensitized to egg (Cohort C)

\begin{tabular}{|c|c|c|c|c|}
\hline $\begin{array}{l}\text { Skin test } \\
\text { positivity }\end{array}$ & $\begin{array}{c}\text { Sensitized } \\
\text { to egg } \\
(n=9) \\
(\%)\end{array}$ & $\begin{array}{c}\text { Not } \\
\text { sensitized } \\
\text { to egg } \\
(n=633) \\
(\%)\end{array}$ & OR $(95 \% \mathrm{Cl})$ & $P$-value \\
\hline $\begin{array}{l}\text { House } \\
\text { dust mite }\end{array}$ & $6(66.7)$ & 37 (5.9) & $32.2(6.5,203.6)$ & $<0.001$ \\
\hline Cat & $3(33.3)$ & $23(3.6)$ & $13.3(2.0,66.1)$ & 0.004 \\
\hline Peanut & $4(44.4)$ & $9(1.4)$ & $55.5(9.1,298.5)$ & $<0.001$ \\
\hline Sesame & $0(0)$ & $9(1.4)$ & - & $>0.999$ \\
\hline
\end{tabular}

\section{Test for trend}

We observed significant changes in the levels of peanut sensitization and overall atopy over time (Figs 1 and 3). In each case the quadratic (nonlinear) components of trend were statistically significant at conventional levels (with $P$-values 0.005 , and 0.024 , respectively). Although levels initially increased from 1989 values (Cohort A) the data suggests that this may have either peaked or started to decline, even though the decline was not significant. The trend in clinical peanut allergy is less clear (Fig. 2). Using the entire cohort as a denominator, neither the linear (0.069) nor quadratic (0.127) components of trend achieve significance at the 5\% level, although the data on the linear component could be considered as borderline significant.

Analysing the data using only the subgroup who underwent SPT as the denominator, levels of clinical peanut allergy did also not appear to be rising ( $P$-value for quadratic trend $=0.499$ ). We feel, however, that this information, using only those who underwent SPT, is spurious as only $72 \%$ of Cohort $\mathrm{C}$ consented to testing.

\section{Discussion}

In the most recent cohort of children born in 2001 (Cohort C), we have found that $2.0 \%$ of children were sensitized to peanut at the age of 3 years. Eleven $(1.2 \%)$ of these children were clinically allergic to peanuts based on food challenge or sensitization status and a good clinical history. In terms of sensitization to peanut, rates for children born in 1989 were $1.3 \%$ (Cohort A) and $2.0 \%$ for children born in 2001 (Cohort C) with a peak occurring in children born in 1994-1996 (3.3\%; Cohort B). Clinical peanut allergy was slightly lower in Cohort $\mathrm{C}(1.2 \%)$ compared to Cohort B (1.4\%), with the lowest figures seen in Cohort $\mathrm{A}$ $(0.5 \%)$. However, the lowest figures for overall allergy were seen in Cohort C $(11.7 \%)$, followed by Cohort A $(12.3 \%)$ and Cohort B (14.8\%).

Comparing the data from Cohort $\mathrm{C}$ with previous studies, we found similar figures of clinical peanut allergy $(1.3 \%)$, to those reported by Sicherer (17) $(0.8 \%)$ for the USA and $1.5 \%$ by Kagan (18) from Canada. Hourihane et al. (11) and $\mathrm{Du}$ Toit et al. (12) recently reported a prevalence of peanut allergy of $1.8 \%$ among 4 - to 5 -year-old and $1.85 \%$ in 4 - to 18 -year-old children in the UK, respectively. Although higher than reported in our Cohort $\mathrm{C}(2.0 \%$ and $1.2 \%$, respectively), the differences between our Cohort $\mathrm{C}$ and that of Hourihane et al. (11) are not statistically significant $(P=0.28$, $P=0.34)$.

Parents of children in Cohort $\mathrm{C}$ sensitized to peanut, were significantly more likely to report suffering from other allergic conditions such as eczema and wheeze, findings confirmed by Grundy et al. (13) and Hourihane et al. (11). This is interesting, as Arshad et al. (19) found wheeze and asthma at 10 years of age to be associated with atopy (positive SPT) at 4 years of age, but not reported wheeze at 4 years. Sensitization to peanut was also associated with sensitization to other allergens (house dust mite, cat, egg and sesame). Grundy et al. (13) reported similar findings. The significance of these associations is difficult to interpret, that is, why peanut sensitization is associated with sensitization to some foods but not to others, for example milk, wheat or fish. However, the association with house dust mite sensitization emphasizes that peanut allergy is mostly present in atopic children. House dust mite sensitization is often considered as a marker for atopy (20).

Mean age of introduction to peanut in the study by Hourihane et al. (11) was 36 months and Grundy (13) reported 18 months as the mean age of introduction. In Cohort $\mathrm{C}$, the mean age of introduction was 36 months, which indicates later introduction of peanuts into the child's diet in Cohort $\mathrm{C}$ and the study performed by Hourihane et al. (11) than Cohort B. This is in line with the COT report 1998 (16), which advises that peanut should not be introduced into the infant's diet before the age of 3 years. Amongst the children who were SPT to peanut at 3 years of age in Cohort C, we had information regarding weaning practices of 628 children. Of 13 children sensitized to peanut, five had eaten peanut and six had not eaten peanut by 6 months of age; we did not have data on two of the children.

Of the 617 children not sensitized to peanut, 215 had eaten peanuts and 402 did not. There was no indication that age of introduction of peanut played a role in sensitization $(P=0.53)$. 
We did not see any significant changes (either increase or decrease) in peanut allergy or sensitization since the release of the COT report in the UK (16), although clinical allergy in Cohort $\mathrm{C}$ was lower than for Cohort $\mathrm{B}$ but this was not significant. This information could be interpreted in two ways. Firstly, one could argue that the lower levels of sensitization to peanut seen in Cohort C, compared to Cohort B may merely be a reflection of the global trend (i.e. higher rates of atopy in Cohort $\mathrm{B}$ compared to Cohorts $\mathrm{A}$ and $\mathrm{C}$ ). Also, it has to be considered that only 1273 of 2878 in Cohort B consented to the medical questionnaire. It may therefore be a highly selective population, but it was not possible to compare atopy between these two groups. One possible limitation of the study is that the children in Cohort A did not undergo food challenges. These children have, however, been followed up for some time (21) and we are confident that the figures reported based on history and sensitization status are correct. Also, diagnosis based on clinical history alone, without oral challenge, tends to over estimate the prevalence of allergy and yet, Cohort A had the lowest prevalence of clinical peanut allergy. In addition, some people may argue that all the children in both Cohorts $\mathrm{B}$ and $\mathrm{C}$ should have undergone DBPCFC rather than OFC. We have recently reported that $\mathrm{OFC}$ in children with immediate objective symptoms is adequate for diagnosing food allergy
(22). Interestingly, the only reason why all these children did not undergo DBPCFC, was parental refusal. One advantage of this study is the comparability of the population studies born in the same geographical location, they were of similar age and assessed by the same research team.

\section{Conclusion}

In summary, we have demonstrated in three cohorts of children born in the same geographical area, Isle of Wight UK, that sensitization to peanut and overall atopy have changed since 1989, with a peak in children born in 1994-1996. No significant changes in clinical allergy appeared between 1994 and 2002. This may not necessarily be attributed to the release of the COT report, as this advice was misunderstood and applied incorrectly by both health care professionals and pregnant women.

\section{Acknowledgements}

The authors gratefully acknowledge the cooperation of the children and parents who have participated in this study. We would also like to thank the research support team at Portsmouth University and the David Hide Asthma and Allergy Research Centre.

\section{References}

1. Bock SA. Prospective appraisal of complaints of adverse reactions to foods in children during the first 3 years of life. Pediatrics 1987;79:683-688.

2. Fuglsang G, Madsen G, Halken S, Jorgensen S, Ostergaard PA, Osterballe O. Adverse reactions to food additives in children with atopic symptoms. Allergy 1994;49:31-37.

3. Zuberbier T, Edenharter G, Worm M, Ehlers I, Reimann S, Hantke T et al. Prevalence of adverse reactions to food in Germany - a population study. Allergy 2004;59:338-345.

4. Jansen JJ, Kardinaal AF, Huijbers G, VliegBoerstra BJ, Martens BP, Ockhuizen T. Prevalence of food allergy and intolerance in the adult Dutch population. J Allergy Clin Immunol 1994;93:446-456.

5. Venter C, Pereira B, Voigt K, Grundy J, Clayton CB, Higgins B et al. Prevalence and cumulative incidence of food hypersensitivity in the first 3 years of life. Allergy 2008;63:354-359.

6. Venter C, Pereira B, Grundy J, Clayton CB, Roberts G, Higgins B et al. Incidence of parentally reported and clinically diagnosed food hypersensitivity in the first year of life. J Allergy Clin Immunol 2006;117:1118-1124.

7. Pereira B, Venter C, Grundy J, Clayton CB, Arshad SH, Dean T. Prevalence of sensitization to food allergens, reported adverse reaction to foods, food avoidance, and food hypersensitivity among teenagers. J Allergy Clin Immunol 2005;116:884-892.

8. Rona RJ, Keil T, Summers C, Gislason D, Zuidmeer L, Sodergren E et al. The prevalence of food allergy: a meta-analysis. $J$ Allergy Clin Immunol 2007;120:638-646.

9. Bock SA, Munoz-Furlong A, Sampson HA. Further fatalities caused by anaphylactic reactions to food, 2001-2006. J Allergy Clin Immunol 2007;119:1016-1018.

10. Eigenmann PA, Zamora SA. An internetbased survey on the circumstances of foodinduced reactions following the diagnosis of IgE-mediated food allergy. Allergy 2002;57:449-453.

11. Hourihane J, Aiken R, Briggs R, Gudgeon LA, Grimshaw KE, DunnGalvin A et al. The impact of government advice to pregnant mothers regarding peanut avoidance on the prevalence of peanut allergy in United Kingdom children at school entry. J Allergy Clin Immunol 2007;119:1197-1202.

12. Du TG, Katz Y, Sasieni P, Mesher D, Maleki SJ, Fisher HR et al. Early consumption of peanuts in infancy is associated with a low prevalence of peanut allergy. $J$ Allergy Clin Immunol 2008;122:984-991.

13. Grundy J, Matthews S, Bateman B, Dean T, Arshad SH. Rising prevalence of allergy to peanut in children: data from 2 sequential cohorts. J Allergy Clin Immunol 2002;110:784-789.
14. Tariq SM, Stevens M, Matthews S, Ridout S, Twiselton R, Hide DW. Cohort study of peanut and tree nut sensitisation by age of 4 years. BMJ 1996;313:514-517.

15. Bateman B, Warner JO, Hutchinson E, Dean T, Rowlandson P, Gant C et al. The effects of a double blind, placebo controlled, artificial food colourings and benzoate preservative challenge on hyperactivity in a general population sample of preschool children. Arch Dis Child 2004;89:506-511.

16. Committee on Toxicity of Chemicals in Food CpatE, Department of Health. COT Consumer products and the environment Peanut allergy. DoH 1998. Crown Copyright. Ref Type: Report

17. Sicherer SH, Munoz-Furlong A, Sampson HA. Prevalence of peanut and tree nut allergy in the United States determined by means of a random digit dial telephone survey: a 5-year follow-up study. J Allergy Clin Immunol 2003;112:1203-1207.

18. Kagan RS, Joseph L, Dufresne C, GrayDonald K, Turnbull E, Pierre YS et al. Prevalence of peanut allergy in primaryschool children in Montreal, Canada. J Allergy Clin Immunol 2003;112:1223-1228.

19. Arshad SH, Kurukulaaratchy RJ, Fenn M, Matthews S. Early life risk factors for current wheeze, asthma, and bronchial hyperresponsiveness at 10 years of age. Chest 2005;127:502-508. 
20. Harrop J, Chinn S, Verlato G, Olivieri M, Norback D, Wjst M et al. Eczema, atopy and allergen exposure in adults: a population-based study. Clin Exp Allergy 2007;37:526-535.
21. Kurukulaaratchy RJ, Fenn M, Matthews S, Arshad SH. Characterisation of atopic and non-atopic wheeze in 10 year old children. Thorax 2004;59:563-568.

22. Venter C, Pereira B, Voigt K, Grundy J, Clayton $\mathrm{CB}$, Gant $\mathrm{C}$ et al. Comparison of open and double-blind placebo-controlled food challenges in diagnosis of food hypersensitivity amongst children. $J$ Hum Nutr Diet 2007;20:565-579. 